\title{
Cannabinoid Addiction: Behavioral Models and Neural Correlates
}

\author{
Rafael Maldonado ${ }^{1}$ and Fernando Rodríguez de Fonseca ${ }^{2}$ \\ ${ }^{1}$ Laboratori de Neurofarmacologia, Facultat de Cienciés de la Salut i de la Vida, Universitat Pompeu Fabra, 08003 \\ Barcelona, Spain, and ²Fundación Hospital Carlos Haya, Unidad de Investigación, 29010 Málaga, Spain
}

The use of cannabis sativa preparations as recreational drugs can be traced back to the earliest civilizations. However, animal models of cannabinoid addiction allowing the exploration of neural correlates of cannabinoid abuse have been developed only recently. We review these models and the role of the CB1 cannabinoid receptor, the main target of natural cannabinoids, and its interaction with opioid and dopamine transmission in reward circuits. Extensive reviews on the molecular basis of cannabinoid action are available elsewhere (Piomelli et al., 2000; Schlicker and Kathmann, 2001).
Neuropsychopharmacological studies have clarified the social controversy on the abuse liability of cannabinoids by demonstrating that such drugs fulfill most of the common features attributed to compounds with reinforcing properties (Table 1). There were several reasons for the delay of such models. (1) The structure and production of ethanol, cocaine, opioids, and nicotine were identified early, whereas naturally occurring psychoactive cannabinoids were not isolated and synthesized until the late 1960s (Mechoulam, 1970). (2) Cannabinoids are hydrophobic substances that redistribute to fat stores with a low rate of excretion. This feature and additional pharmacokinetic properties made it difficult to characterize a cannabinoid receptor and precluded the identification of neuroadaptions associated with the onset of dependence and withdrawal. (3) Initial studies of cannabinoidinduced reinforcement used high doses unrelated to those that induce subjective effects in humans. Most early findings pointed to an aversive profile for cannabinoids (Elsmore and Fletcher, 1972).

After the identification of new synthetic cannabinoids, a cannabinoid receptor was identified and cloned in the late 1980s (Matsuda et al., 1990) (Fig. 1). By using a more rational approach, the subjective effects of cannabinoids have been studied with classical paradigms in animal models such as drug discrimination. Motivational properties and indirect reinforcing measures were identified with intracranial self-stimulation (ICSS) and conditioned place preference paradigms (CPPs). The direct reinforcing properties of cannabinoids were demonstrated recently with intravenous self-administration (ISA) (Gardner and Vorel, 1998). Additionally, the induction of tolerance and dependence and the identification of a cannabinoid withdrawal syndrome have been verified. Biochemical and electrophysiological studies have also clarified the effects of cannabinoids on brain circuits responsible

This work has been supported by grants from Plan Nacional Sobre Drogas, European Communities BIOMED2 Grant PL 982267 and Fifth Framework Programme, Grant QLRT-2000-01691, Generalitat de Catalunya (Research Distinction), Human Frontier Science Program Organization (RG0077/2000-B), Ministerio de Ciencia y Tecnología (SAF 2000-0101), Fondo de Investigación Sanitaria (FIS 2001-00654), and Laboratorios Dr. Esteve.

Correspondence should be addressed to Rafael Maldonado, Laboratori de Neurofarmacologia, Facultat de Cienciès de la Salut i de la Vida, Universitat Pompeu Fabra, C/Dr. Aiguader 08003 Barcelona, Spain, E-mail: rafael.maldonado@cexs.upf.es, or Fernando Rodríguez de Fonseca, Unidad de Investigación, Fundación Hospital Carlos Haya, Avda Carlos Haya s/n 7 Planta, Pabellón A, 29010 Malaga, Spain, E-mail: frfonseca@hch.sas.junta-andalucia.es.

Copyright (ㄷ) 2002 Society for Neuroscience $0270-6474 / 02 / 223326-06 \$ 15.00 / 0$ for the addictive properties of drugs. They include the analysis of acute and chronic cannabinoid actions on mesolimbic dopamine (DA) neurons, cannabinoid modulation of glutamate and GABA transmission in reward circuits, and cannabinoid interactions with neuropeptides relevant for processing motivation, such as the opioid peptides and corticotropin-releasing factor (CRF). Most recently, $\mathrm{CB} 1$ cannabinoid receptor $(\mathrm{CB} 1 \mathrm{R})$ and other knock-out (KO) mice deficient in different components of the endogenous opioid system were generated and used to understand the contribution of these endogenous systems to cannabinoid dependence (Ledent et al., 1999; Valverde et al., 2000; Zimmer et al., 1999, 2001; Ghozland et al., 2002).

\section{Behavioral models for studying cannabinoid motivational and reinforcing properties \\ Drug discrimination}

Early studies identified the discriminative stimulus properties of $\Delta^{9}$-tetrahydrocannabinol (THC), the main psychoactive constituent of cannabis. Because animals did not easily self-administer cannabinoids, initial studies analyzed the subjective properties of cannabinoids with this task. Animals easily associate the pharmacological properties of low doses of THC $(0.20 \mathrm{mg} / \mathrm{kg})$ with a correct response for a reward (i.e., food) in a two-lever drug discrimination task (Jarbe et al., 1976). The discriminative stimulus effects of THC are pharmacologically selective. Noncannabinoid drugs generally do not substitute for THC, whereas cannabinomimetic drugs fully substitute for THC in pigeons, rats, and monkeys (Wiley et al., 1995). A GABAergic component may be involved in cannabinoid drug discrimination, as revealed by the partial substitution elicited by diazepam (Wiley and Martin, 1999). Cannabinoid discriminative effects are prevented by pretreatment with the CB1R antagonist SR141716A (Wiley et al., 1995). Anandamide and stable analogs of this endocannabinoid do not fully substitute for THC, indicating a different pharmacological profile for natural and synthetic cannabinoids and endocannabinoids (Wiley, 1999).

\section{Conditioned place preference paradigms and conditioned taste aversion}

Initial studies with THC showed that this cannabinoid elicits aversive responses in both CPP and conditioned taste aversion (CTA) procedures (Elsmore and Fletcher, 1972). The rationale of these Pavlovian tests is to establish conditioned associations 


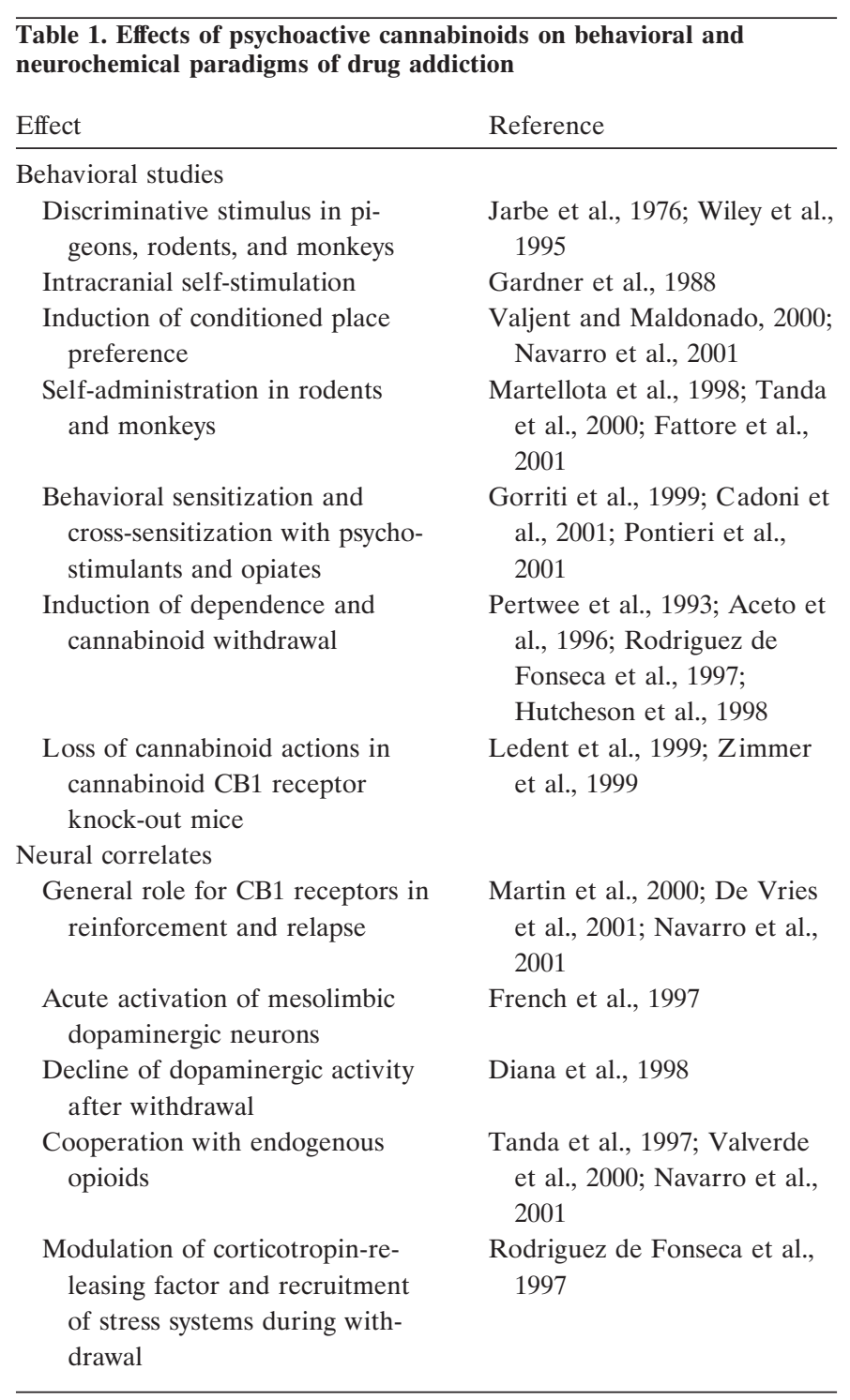

between certain environments or a certain taste and the acute motivational actions of the drug tested. Positive rewarding effects are associated with place preference. However, several abused drugs produce CTA when paired with a certain flavor. THC and other cannabinoid agonists induce CTA and place aversion. These aversive effects are dependent on two variables: high doses induce robust aversion, whereas low doses induce aversion only when tested in naive animals (Gardner and Vorel, 1998). In fact, preexposure to cannabinoids previous to conditioning eliminates the aversive component of cannabinoid effects, resulting in the development of CPP (Valjent and Maldonado, 2000). This aversive effect appears to be mediated by CB1Rs (Chaperon et al., 1998) and to be dependent on endogenous dynorphin transmission (Zimmer et al., 2001) through the activation of $\kappa$ opioid receptors (KORs) (Ghozland et al., 2002). CPP induced by cannabinoid agonists can also be prevented by CB1R blockade (Navarro et al., 2001), and the endogenous opioid system participates in this response. In agreement, THC-induced CPP was suppressed in $\mathrm{KO}$ mice deficient in $\mu$ opioid receptors (MORs) (Fig. 2 ) but was unaffected in mice lacking $\delta$ opioid receptors (DORs) or KORs, suggesting a selective involvement of MORs in this THC response (Ghozland et al., 2002). This interaction between cannabinoid and opioid systems seems to be bidirectional given that the rewarding effects of morphine in the CPP paradigm are blocked in CB1R KO mice (Martin et al., 2000). Furthermore, the CB1R antagonist SR141716A blocks acquisition of morphine $\mathrm{CPP}$, as well as the rewarding effects of other drugs of abuse (Chaperon et al., 1998).

\section{Intracranial self-stimulation}

This behavioral paradigm allows direct in vivo monitoring of drug effects on brain reward circuits by evaluating self-delivery of rewarding electrical stimulation of the medial forebrain bundle. Drugs capable of activating reward circuits facilitate ICSS. Low doses of THC enhance ICSS by lowering reward thresholds (Gardner et al., 1988). This effect varies in different rat strains. Lewis rats, which are very sensitive to positive reinforcers, exhibit the most robust effects (Gardner and Vorel, 1998). The CB1R antagonist SR141716A decreases sensitivity to electrical stimulation, an effect observed also after withdrawal from THC (1 $\mathrm{mg} / \mathrm{kg}$ ) treatment (Gardner and Vorel, 1998). These observations suggest that $\mathrm{CB} 1 \mathrm{R}$ activation in reward circuits facilitates the effects of positive reinforcers, although the magnitude of this effect has been questioned (Arnold et al., 2001). Naloxone blocks the facilitatory effects of THC on ICSS, suggesting an opioid component in these THC-induced rewarding effects (Gardner and Vorel, 1998).

\section{Intravenous self-administration}

Since 1970, all attempts to obtain a robust procedure for THC self-administration have failed. This failure has been fundamental to claims of a differential status for cannabinoids with respect to major abused drugs. The availability of new cannabimimetic compounds that activate CB1Rs and have different pharmacokinetic properties than THC led to the first observation of cannabinoid ISA in mice. Drug-naive mice self-administer the aminoalkylindole WIN 55,212-2 (Martellotta et al., 1998), the bicyclic cannabinoid CP 55,940, and the THC derivative HU-210 (Navarro et al., 2001). These compounds cover the three major types of cannabinoid-like chemicals. Rats also exhibit ISA (Fattore et al., 2001) of synthetic cannabinoid agonists. In all cases, an inverted U-shaped relationship between cannabinoid dose and injection frequency is observed, as for most self-administered drugs. Although THC is unable to sustain ISA in mice and rats, self-administration of synthetic cannabinomimetic compounds was counteracted by the antagonist SR141716A, indicating a major role for CB1Rs. The fact that squirrel monkeys (Tanda et al., 2000) self-administer THC, an effect than can also be precluded by CB1R antagonism, indicates species-specific differences in the pharmacokinetics and pharmacodynamics of THC between primates and rodents that preclude the observation of THC self-administration in murine models. In any case, both ISA paradigms require manipulations of the motivational state of the animal to achieve stable self-administration patterns. Rodents must be food restricted, whereas THC self-administration in monkeys is achieved after previous acquisition of cocaine selfadministration. Cannabinoid self-administration is dependent not only on CB1Rs, but an opioid component is also observed; naloxone blocks this behavior in mice and rats (Fattore et al., 2001; Navarro et al., 2001), whereas naltrexone blocks THC ISA in monkeys (Tanda et al., 1997, 2000). This interaction between cannabinoid and opioid systems is also bi-directional. Morphine ISA is abolished in CB1R KO mice (Ledent et al., 1999). 
Figure 1. Molecular targets of major abused drugs. Cannabinoids, like opiates, activate a G-protein-coupled receptor, in this case the CB1R, which couples to transduction mechanisms, mainly adenylyl cyclase $(A C)$, and voltage-gated potassium, and calcium channels through the small GTPbinding proteins $G_{s / o l f}$ and $G_{i / o}$. CB1 receptors thereby modulate the resting membrane potential and intracellular concentrations of cAMP. Subsequent modification of the activity of specific protein kinases, primarily PKA, but also mitogen-activated protein kinases, leads to both acute responses (modulation of neurotransmitter release or firing rates) and long-term adaptations associated with dependence and withdrawal.

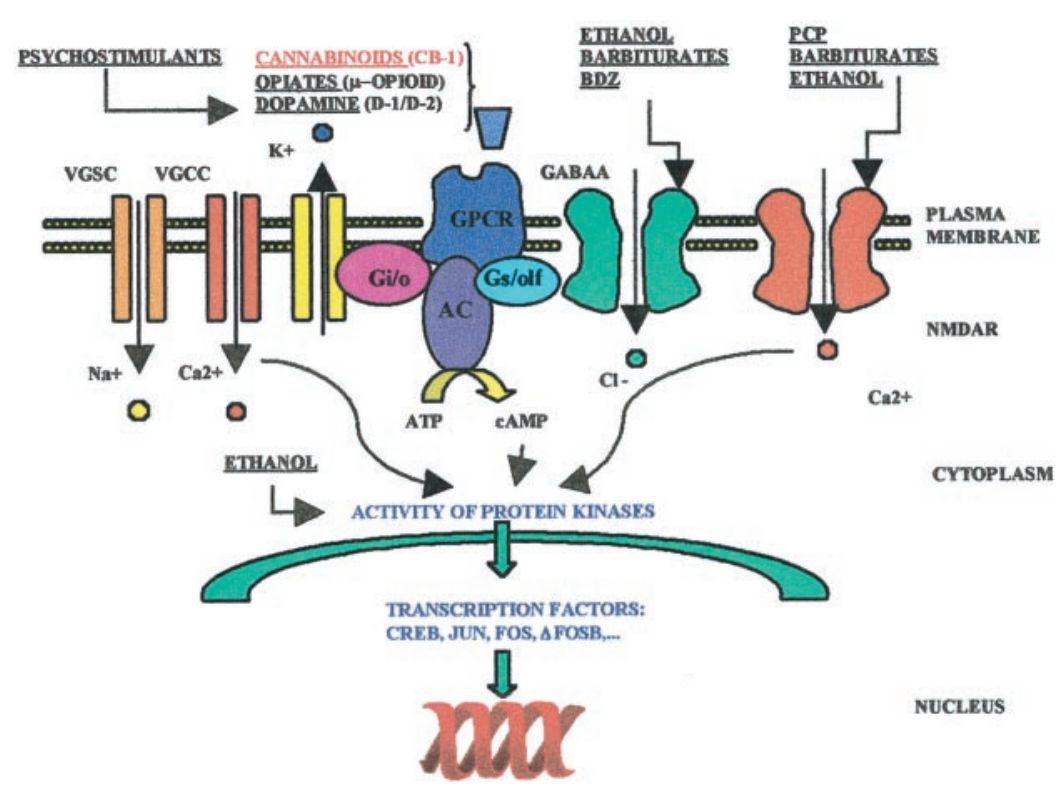

ioral sensitization (Cadoni et al., 2001), similar to other drugs of abuse. Chronic cannabinoid administration also produces crosssensitization to the locomotor effects of psychostimulants (Gorriti et al., 1999) and opioids (Pontieri et al., 2001).

\section{Behavioral models for studying cannabinoid tolerance, dependence, and withdrawal}

Tolerance

Chronic administration of CB1R agonists leads to tolerance to most responses. Indeed, several studies have shown tolerance to cannabinoid effects on antinociception, locomotion, hypothermia, catalepsy, suppression of operant behavior, gastrointestinal transit, body weight, cardiovascular actions, anticonvulsant activity, ataxia, and corticosterone release. This tolerance occurs in rodents, pigeons, dogs, and monkeys (Abood and Martin, 1992). The development of cannabinoid tolerance is rapid, often occurring on the second administration (Abood and Martin, 1992). Tolerance is maximal after short-term cannabinoid treatment (Bass and Martin, 2000).

Different pharmacokinetic mechanisms are involved in cannabinoid tolerance, including changes in drug absorption, distribution, biotransformation, and excretion. However, the role of such pharmacokinetic mechanisms seems minor (Dewey et al., 1972). In contrast, pharmacodynamic events play a crucial role in canna-
Figure 2. Involvement of the endogenous opioid system in cannabinoid motivational properties, tolerance, and dependence. $A$, THC-induced CPP is abolished in MOR $\mathrm{KO}$ mice. Scores are calculated as the difference between test and preconditioning time spent in the drug-paired compartment (from Ghozland et al., 2002). B, Tolerance to THC-induced antinociception is reduced in $\mathrm{KO}$ mice deficient in the pre-proenkephalin gene (from Valverde et al., 2000). $C$, Severity of SR141716Aprecipitated THC withdrawal syndrome is

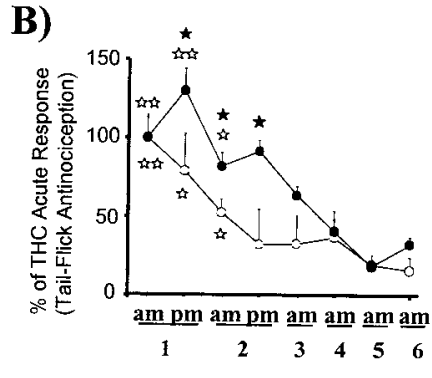

C)

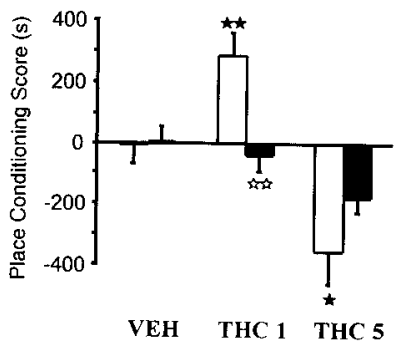

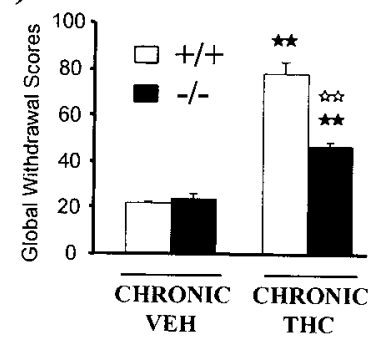

attenuated in KO mice deficient in the pre-proenkephalin gene. A global withdrawal score was calculated for each animal by giving each individual sign (tremor, wet dog shakes, ptosis, front paw tremor, ataxia, mastication, hunched posture, sniffing, piloerection, and penile lick) a proportional weight (from Valverde et al., 2000). Values are expressed as mean \pm SEM; $\gg p<0.05, \gg p<0.01$, comparison between treatments; $\triangleleft 4 p<0.05, \longleftrightarrow<4<p<$ 0.01 , comparison between genotypes (one-way ANOVA). 
binoid tolerance. Indeed, a significant decrease in the total number of CB1Rs (Rodriguez de Fonseca et al., 1994) and levels of CB1R mRNA occurs in several brain areas during chronic cannabinoid administration (Romero et al., 1998). A widespread decrease in mRNA levels of $\mathrm{G}_{\alpha \mathrm{i}^{-}}$and $\mathrm{G}_{\alpha \mathrm{s}}$-proteins accompanies chronic treatment with cannabinoids (Rubino et al., 1997). Changes in G-protein expression are related to desensitization of CB1Rs. Reductions of cannabinoid agonist-stimulated $\left[{ }^{35} \mathrm{~S}\right] \mathrm{GTP} \gamma \mathrm{S}$ binding are seen in most brain regions of rats chronically treated with cannabinoids (Sim et al., 1996).

Cross-tolerance exists between different exogenous CB1R agonists with respect to antinociception, hypolocomotion, catalepsy, and hypothermia (Pertwee et al., 1993). Cross-tolerance between opioid and cannabinoid compounds is also common. THC and morphine elicit cross-tolerance in mice for nociception and cardiac rhythm (Hine 1985). However, no modification (Martin, 1985) or even a potentiation (Melvin et al., 1993) of cannabinoid antinociception has been reported in morphine-dependent rats. Cross-tolerance between CB1R agonists and KOR agonists on antinociception has also been reported (Rowen et al., 1998). Similarly, administration of antisense oligodeoxynucleotides to block KOR expression increases development of tolerance to THC (Rowen et al., 1998). The development of THC tolerance is slightly modified in KOR KO mice but is unaltered in either MOR or DOR KO mice (Ghozland et al., 2002). These results agree with increased release of the endogenous KOR agonist dynorphin induced by acute THC. However, there appears to be no correlation between THC-induced dynorphin A release and development of tolerance to THC antinociception (Mason et al., 1999), and this THC tolerance is not modified in prodynorphin gene $\mathrm{KO}$ mice (Zimmer et al., 2001). Interestingly, KO mice lacking the pre-proenkephalin gene show a decrease in the development of tolerance to THC antinociception and a slight attenuation of tolerance to THC hypolocomotion (Fig. 2), suggesting the involvement of endogenous opioid peptides derived from this precursor (Valverde et al., 2000).

\section{Cannabinoid dependence and withdrawal}

Several studies have reported the absence of somatic signs of spontaneous withdrawal after chronic THC treatment in rodents, pigeons, dogs, and monkeys, even at extremely high doses (Diana et al., 1998; Aceto et al., 2001). However, a recent study has reported somatic signs of spontaneous abstinence after abrupt interruption of chronic treatment with the cannabinoid agonist WIN 55,212-2 (Aceto et al., 2001), perhaps because of different pharmacokinetic properties of THC and WIN 55,212-2. In contrast, administration of the CB1R antagonist SR141716A in animals chronically treated with THC can precipitate somatic manifestations of withdrawal. In rodents, a large number of somatic signs and an absence of vegetative manifestations characterize cannabinoid withdrawal. The most characteristic somatic manifestations in rodents are wet dog shakes, head shakes, facial rubbing, front paw tremor, ataxia, hunched posture, body tremor, ptosis, piloerection, hypolocomotion, mastication, licking, rubbing, and scratching (Aceto et al., 1996, 2001; Hutcheson et al., 1998; Ledent et al., 1999). Dramatic motor impairments also occur during cannabinoid withdrawal (Hutcheson et al., 1998; Tzavara et al., 2000). Doses of THC required to induce dependence in rodents are very high, and SR141716A-precipitated withdrawal is seen after chronic administration of THC at doses of 10-100 mg/ $\mathrm{kg}$ daily (Aceto et al., 1996, 2001; Hutcheson et al., 1998; Ledent et al., 1999; Tzavara et al., 2000). CB1Rs mediate somatic manifestations of cannabinoid withdrawal. Thus, SR141716A administration in CB1R KO mice receiving chronic THC treatment fails to precipitate any manifestation of cannabinoid abstinence (Ledent et al., 1999).

Bi-directional interactions between cannabinoid and opioid dependence have been reported. Administration of the CB1R antagonist SR141716A precipitates withdrawal in morphine-dependent rats (Navarro et al., 1998), whereas naloxone precipitated withdrawal in cannabinoid-dependent rats (Navarro et al., 1998). However, these interactions are not observed in cannabinoid- and opioid-dependent mice after naloxone and SR141716A challenge (Litchtman et al., 2001). Furthermore, the severity of cannabinoid abstinence is not modified in MOR, DOR, or KOR KO mice (Ghozland et al., 2002) or in prodynorphin KO mice (Zimmer et al., 2001) chronically treated with THC. However, the severity of cannabinoid withdrawal is decreased in THC-dependent $\mathrm{KO}$ mice lacking the pre-proenkephalin gene (Fig. 2) (Valverde et al., 2000) and in MOR KO mice chronically treated with higher doses of THC (Litchtman et al., 2001). Therefore, endogenous opioid peptides derived from pre-proenkephalin are important for the somatic expression of cannabinoid abstinence by acting on MOR and other opioid receptors. In contrast, the severity of morphine withdrawal is attenuated in CB1R KO mice (Ledent et al., 1999). The use of combinatorial opioid receptor KO mice lacking two or three opioid receptors will clarify these findings.

\section{Neural correlates of cannabinoid withdrawal}

Common features of withdrawal syndromes produced by several drugs of abuse include elevations in extracellular CRF levels in the mesolimbic system and a marked inhibition of mesolimbic DA activity (Koob, 1996). Such changes have been reported during cannabinoid withdrawal. Increased CRF release and enhancement of Fos immunoreactivity occur in the central amygdala during SR141716A-precipitated cannabinoid withdrawal (Rodriguez de Fonseca et al., 1997). This alteration of limbic system CRF function may mediate the stress-like symptoms and negative affect that accompany cannabinoid withdrawal. In agreement with this hypothesis, the spontaneous firing rate of VTA DA neurons is reduced during cannabinoid abstinence (Diana et al., 1998), which is likely related to the aversive and dysphoric consequences of cannabinoid withdrawal.

Similar to opioids, cannabinoid withdrawal is associated with compensatory changes in the cAMP pathway. Initially, acute activation of CB1Rs inhibits adenylyl cyclase activity (Fig. 1). In contrast, SR141716A-precipitated THC withdrawal increases adenylyl cyclase activity in vivo (Hutcheson et al., 1998). Despite common biochemical mechanisms, different brain structures are involved in the physical manifestations of opioid and cannabinoid withdrawal. Brainstem structures, such as the locus coeruleus, are responsible for the somatic signs of opioid withdrawal (Maldonado et al., 1992), but the cerebellum plays a crucial role in the somatic expression of THC withdrawal (Hutcheson et al., 1998; Tzavara et al., 2000). Basal, forskolin-, and calcium/calmodulinstimulated adenylyl cyclase activities were selectively increased in the cerebellum but not in other brain structures (PFC, hippocampus, striatum, and periaqueductal gray matter) during cannabinoid withdrawal (Hutcheson et al., 1998). Furthermore, cannabinoid abstinence is markedly reduced when cAMP-dependent protein kinase is activated in the cerebellum (Tzavara et al., 2000). 


\section{Concluding remarks}

Different animal models are now available to evaluate cannabinoid dependence and abuse liability. These cannabinoid properties are revealed in paradigms similar to those used for other drugs of abuse. However, particular experimental conditions are required to show cannabinoid rewarding properties in CPP and ISA paradigms. Similarly, cannabinoid dependence typically requires high agonist doses and antagonist challenge. These models have provided a better understanding of the neurobiological mechanisms involved in THC actions and have revealed commonalities between cannabinoids and other drugs of abuse with respect to the addictive processes. Thus, the mesolimbic DA system is clearly involved in the rewarding properties of cannabinoids as well as in the motivational consequences of cannabinoid withdrawal. An alteration in mesolimbic CRF function is also related to the dysphoric effects of cannabinoid abstinence. Bi-directional interactions between the endogenous cannabinoid and opioid systems are crucial for cannabinoid motivational properties and the development of cannabinoid tolerance and dependence.

\section{REFERENCES}

Abood ME, Martin BR (1992) Neurobiology of marijuana abuse. Trends Pharmacol Sci 13:201-207.

Aceto MD, Scates SM, Lowe JA, Martin BP (1996) Dependence on delta 9-tetrahydrocannabinol: studies on precipitated and abrupt withdrawal. J Pharmacol Exp Ther 278:1290-1295.

Aceto MD, Scates SM, Lowe JA, Martin BP (2001) Spontaneous and precipitated withdrawal with a synthetic cannabinoid, WIN 55,212-2. Eur J Pharmacol 416:75-81.

Arnold JC, Hunt GE, McGregor IS (2001) Effects of the cannabinoid receptor agonist $\mathrm{CP} 55,940$ and the cannabinoid receptor antagonist SR 141716 on intracranial self-stimulation in Lewis rats. Life Sci 70:97-108.

Bass CE, Martin BR (2000) Time course for the induction and maintenance of tolerance to delta-9-tetrahydrocannabinol in mice. Drug Alcohol Depend 60:113-119.

Cadoni C, Pisanu A, Solinas M, Acquas E, Di Chiara G (2001) Behavioural sensitization after repeated exposure to delta(9)tetrahydrocannabinol and cross-sensitization with morphine. Psychopharmacology 158:259-266.

Chaperon F, Soubrie P, Puech AJ, Thiebot MH (1998) Involvement of central cannabinoid (CB1) receptors in the establishment of place conditioning in rats. Psychopharmacology 135:324-332.

De Vries TJ, Shaham Y, Homberg JR, Crombag H, Schuurman K, Dieben J, Vanderschuren LJ, Schoffelmeer AN (2001) A cannabinoid mechanism in relapse to cocaine seeking. Nat Med 7:1151-1154.

Dewey WL, Jenkins J, O'Rourke T, Harris LS (1972) The effects of chronic administration of trans- $\Delta^{9}$-tetrahydrocannabinol on behavior and the cardiovascular system of dogs. Arch Int Pharmacodyn Ther 198:118-131.

Diana M, Melis M, Muntoni AL, Gessa GL (1998) Mesolimbic dopaminergic decline after cannabinoid withdrawal. Proc Natl Acad Sci USA 95:10269-10273.

Elsmore RF, Fletcher GV (1972) Delta-9-tetrahydrocannabinol: aversive effects at high dosages. Science 175:911-912.

Fattore L, Cossu G, Martellotta CM, Fratta W (2001) Intravenous selfadministration of the cannabinoid CB1 receptor agonist WIN 55,212-2 in rats. Psychopharmacology 156:410-416.

French ED, Dillon K, Wu X (1997) Cannabinoids excite dopamine neurons in the ventral tegmentum and substantia nigra. NeuroReport $8: 649-652$.

Gardner EL, Vorel SR (1998) Cannabinoid transmission and rewardrelated events. Neurobiol Dis 5:502-533.

Gardner EL, Paredes W, Smith D, Donner A, Milling C, Cohen D, Morrison D (1988) Facilitation of brain stimulation reward by delta 9-tetrahydrocannabinol. Psychopharmacology 96:142-144.

Ghozland S, Mathews H, Simonin F, Filliol D, Kieffer BL, Maldonado R (2002) Motivational effects of cannabinoids are mediated by $\mu$ - and -opioid receptors. J Neurosci 22:1146-1154.

Giuffrida A, Parsons LH, Kerr TM, Rodriguez de Fonseca F, Navarro M, Piomelli D (1999) Dopamine activation of endogenous cannabinoid signaling in dorsal striatum. Nat Neurosci 2:358-363.

Gorriti MA, Rodriguez de Fonseca F, Navarro M, Palomo T (1999) Chronic (-)-delta-9-tetrahydrocannabinol treatment induces sensitization to the psychomotor effects of amphetamine in rats. Eur J Pharmacol 365:133-142.
Hine B (1985) Morphine and delta 9-tetrahydrocannabinol: two-way cross tolerance for antinociceptive and heart-rate responses in the rat. Psychopharmacology 87:34-38.

Hutcheson DM, Tzavara ET, Smadja C, Valjent E, Roques BP, Hanoune J, Maldonado R (1998) Behavioral and biochemical evidence for signs of abstinence in mice chronically treated with delta-9tetrahydrocannabinol. Br J Pharmacol 125:1567-1577.

Jarbe TU, Johansson JO, Henriksson BG (1976) Characteristics of tetrahydrocannabinol (THC)-produced discrimination in rats. Psychopharmacology 48:181-187.

Koob GF (1996) Drug addition: The yin and yang of hedonic homeostasis. Neuron 16:893-896

Ledent C, Valverde O, Cossu G, Petitet F, Aubert JF, Beslot F, Bohme GA, Imperato A, Pedrazzini T, Roques BP, Vassart G, Fratta W, Parmentier M (1999) Unresponsiveness to cannabinoids and reduced addictive effects of opiates in CB1 receptor knockout mice. Science 283:401-404.

Litchtman AH, Sheikh HH, Loh SM, Martin BR (2001) Opioid and cannabinoid modulation of precipitated withdrawal in delta-9tetrahydrocanabinol and morphine-dependent mice. J Pharmacol Exp Ther 298:1007-1014.

Maldonado R, Stinus L, Gold LH, Koob GF (1992) Role of different brain structures in the expression of the physical morphine withdrawal syndrome. J Pharmacol Exp Ther 261:669-677.

Martellotta MC, Cossu G, Fattore L, Gessa GL, Fratta W (1998) Selfadministration of the cannabinoid receptor agonist WIN 55,212-2 in drug-naive mice. Neuroscience 85:327-330.

Martin BR (1985) Characterisation of the antinociceptive activity of intravenously administered delta 9-tetrahydrocannabinol in mice. In: Marihuana '84, Proceeding of the Oxford Symposium on Cannabis (Harvey DJ, ed), pp 685-692. Oxford, UK: IRL.

Martin M, Ledent C, Parmentier M, Maldonado R, Valverde O (2000) Cocaine, but not morphine, induces conditioned place preference and sensitization to locomotor responses in CB1 knockout mice. Eur J Neurosci 12:4038-4046.

Mason DJ, Lowe J, Welch SP (1999) Cannabinoid modulation of dynorphin A: correlation to cannabinoid-induced antinociception. Eur J Pharmacol 378:237-248.

Matsuda LA, Lolait SJ, Brownstein MJ, Young AC, Bonner TI (1990) Structure of a cannabinoid receptor and functional expression of the cloned cDNA. Nature 346:561-564.

Mechoulam R (1970) Marihuana chemistry. Science 168:1159-1166.

Melvin LS, Milne GM, Jhonson MR, Subramaniam B, Wilken GH, Howlett AC (1993) Structure-activity relationships for cannabinoid receptor-binding and analgesic activity: studies of bicyclic cannabinoid analogs. Mol Pharmacol 44:1008-1015.

Navarro M, Chowen J, Carrera MRA, Del Arco I, Villanua MA, Martin Y, Roberts AJ, Koob GF, Rodriguez de Fonseca F (1998) CB1 cannabinoid receptor antagonist-induced opiate withdrawal in morphinedependent rats. NeuroReport 9:3397-3402.

Navarro M, Carrera MR, Fratta W, Valverde O, Cossu G, Fattore L, Chowen JA, Gomez R, Del Arco I, Villanua MA, Maldonado R, Koob GF, de Fonseca FR (2001) Functional interaction between opioid and cannabinoid receptors in drug self-administration. J Neurosci 21:5344-5350.

Pertwee RG, Stevenson LA, Griffin G (1993) Cross-tolerance between delta-9-tetrahydrocannabinol and the cannabimimetic agents, CP 55,940, W IN 55,212-2 and anandamide. Br J Pharmacol 110:1483-1490.

Piomelli D, Giuffrida A, Calignano A, Rodriguez de Fonseca F (2000) The endocannabinoid system as a target for therapeutic drugs. Trends Pharmacol Sci 21:218-224.

Pontieri FE, Monnazzi P, Scontrini A, Buttarelli FR, Patacchioli FR (2001) Behavioral sensitization to heroin by cannabinoid pretreatment in the rat. Eur J Pharmacol 421:R1-3.

Rodriguez de Fonseca F, Gorriti MA, Fernandez-Ruiz JJ, Palomo T, Ramos JA (1994) Downregulation of rat brain cannabinoid binding sites after chronic delta-9-tetrahydrocannabinol treatment. Pharmacol Biochem Behav 47:33-40.

Rodriguez de Fonseca F, Carrera MR, Navarro M, Koob GF, Weiss F (1997) Activation of corticotropin-releasing factor in the limbic system during cannabinoid withdrawal. Science 276:2050-2054.

Romero J, Berrendero F, Manzanares J, Pérez A, Corchero J, Fuentes A, Fernández-Ruiz JJ, Ramos JA (1998) Time-course of the cannabinoid receptor down-regulation in the adult rat brain caused by repeated exposure to delta 9-tetrahydrocannabinol. Synapse 30:298-308.

Rowen DW, Embrey JP, Moore CH, Welch SP (1998) Antisense oligodeoxynucleotides to the kappa $_{1}$ receptor enhance delta-9-THCinduced antinociceptive tolerance. Pharmacol Biochem Behav 59:399-404.

Rubino T, Patrini G, Parenti G, Massi P, Parolaro D (1997) Chronic treatment with a synthetic cannabinoid CP55,940 alters G protein expression in the rat central nervous system. Mol Brain Res 44:191-197.

Schlicker E, Kathmann M (2001) Modulation of transmitter release via presynaptic cannabinoid receptors. Trends Pharmacol Sci 22:565-572. Sim LJ, Hampson RE, Deadwyler SA, Childers SR (1996) Effects of 
chronic treatment with delta-9-tetrahydrocannabinol on cannabinoidstimulated $\left[{ }^{35} \mathrm{~S}\right] \mathrm{GTP} \gamma \mathrm{S}$ autoradiography in rat brain. J Neurosci 16:8057-8066.

Tanda G, Pontieri FE, Di Chiara G (1997) Cannabinoid and heroin activation of mesolimbic dopamine transmission by a common mu1 opioid receptor mechanism. Science 276:2048-2050.

Tanda G, Munzar P, Goldberg SR (2000) Self-administration behavior is maintained by the psychoactive ingredient of marijuana in squirrel monkeys. Nat Neurosci 3:1073-1074.

Tzavara ET, Valjent E, Firmo C, Mas M, Beslot F, Defer N, Roques BP, Hanoune J, Maldonado R (2000) Cannabinoid withdrawal is dependent upon PKA activation in the cerebellum. Eur $\mathrm{J}$ Neurosci 12:1038-1046.

Valjent E, Maldonado R (2000) A behavioural model to reveal place preference to delta 9-tetrahydrocannabinol in mice. Psychopharmacology 147:436-438.

Valverde O, Maldonado R, Valjent E, Zimmer AM, Zimmer A (2000)
Cannabinoid withdrawal syndrome is reduced in pre-proenkephalin knock-out mice. J Neurosci 20:9284-9289.

Wiley JL (1999) Cannabis: discrimination of "internal bliss"? Pharmacol Biochem Behav 64:257-260.

Wiley JL, Martin BR (1999) Effects of SR141716A on diazepam substitution for delta 9-tetrahydrocannabinol in rat drug discrimination. Pharmacol Biochem Behav 64:519-522.

Wiley JL, Huffman JW, Balster RL, Martin BR (1995) Pharmacological specificity of the discriminative stimulus effects of delta 9-tetrahydrocannabinol in rhesus monkeys. Drug Alcohol Depend 40:81-86.

Zimmer A, Zimmer AM, Hohmann AG, Herkenham M, Bonner TI (1999) Increased mortality, hypoactivity, and hypoalgesia in cannabinoid CB1 receptor knockout mice. Proc Natl Acad Sci USA 96:5780-5785.

Zimmer A, Valjent E, Konig M, Zimmer AM, Robledo P, Hahn H, Valverde O, Maldonado R (2001) Absence of $\Delta$-9-tetrahydrocannabinol dysphoric effects in dynorphin-deficient mice. J Neurosci 21 9499-9505. 